\title{
Host-Parasite Relationships in Root-Knot Disease of White Mulberry
}

P. Castillo, Research Nematologist, Instituto de Agricultura Sostenible, Consejo Superior de Investigaciones Cientificas (IAS-CSIC), Apdo. 4084, 14080-Córdoba, Spain; M. Di Vito and N. Vovlas, Nematologist Research Leaders, Istituto di Nematologia Agraria, Consiglio Nazionale delle Ricerche, Via G. Amendola 165/a, 70126-Bari, Italy; and R. M. Jiménez-Díaz, Professor, IAS-CSIC and Escuela Técnica Superior de Ingenieros Agrónomos y Montes (ETSIAM), Universidad de Córdoba, Apdo. 3048, 14080 Córdoba

\begin{abstract}
Castillo, P., Di Vito, M., Vovlas, N., and Jiménez-Díaz, R. M. 2001. Host-parasite relationships in root-knot disease of white mulberry. Plant Dis. 85:277-281.

Severe infections of white mulberry feeder roots and heavy soil infestations by Meloidogyne arenaria race 2 were found in southern Spain. This is the first record of M. arenaria on white mulberry in Europe. Morphometric observations, analysis of the esterase electrophoretic pattern, and artificial inoculations of race differentials were used to characterize nematodes. Nematode-induced mature galls were spherical and usually contained one or more females, males, and egg masses with eggs. Feeding sites were characterized by the development of giant cells that contained granular cytoplasm and many hypertrophied nuclei. Giant cell cytoplasm was aggregated along a thickened cell wall. Vascular tissues within galls appeared disorganized. The relationship between the initial nematode population density $(P i)$ in a series from 0 to 1,024 eggs and juveniles $/ \mathrm{cm}^{3}$ soil and growth of white mulberry seedlings was tested in the greenhouse. A Seinhorst model was fitted to plant height and top fresh weight. Tolerance limits of white mulberry to $M$. arenaria race 2 for plant height and top fresh weight were, respectively, 1.1 and 1.38 eggs and juveniles $/ \mathrm{cm}^{3}$ soil. The minimum relative values for plant height and top fresh weight were 0 at $P i \geq 64$ and $P i \geq 128$ eggs and juveniles $/ \mathrm{cm}^{3}$ soil, respectively. Maximum nematode reproduction rate was 435 -fold at the lowest $P i$.
\end{abstract}

Additional keywords: histopathology, Morus alba, pathogenicity, threshold limit

Severe feeder-root infections of garden grown white mulberry trees and heavy soil infestations by Meloidogyne arenaria (Neal) Chitwood were found recently at two localities in Córdoba and Sevilla provinces in Andalucía, southern Spain. This is the first recorded infection of white mulberry by this root-knot nematode in Europe. The highly devastated root system and the abundance of characteristic spherical galls suggested that specialized nematode-plant relationships might occur.

White mulberry (Morus alba L.) is a perennial tree of the Moraceae family that originates from the lower slopes of the Himalayas (17). This tree can grow under climatic conditions ranging from temperate to tropical, and is economically important in China, Egypt, and India, where the foliage serves as food for the monophagous silk worm (Bombix mori L.) $(2,25,26)$. In addition, mulberry plantings play a role in a sustainable strategy for soil and water conservation in north China (26).

Corresponding author: P. Castillo

E-mail: ag1cascp@lucano.uco.es

Accepted for publication 12 November 2000.

Publication no. D-2001-0108-02R

(C) 2001 The American Phytopathological Society
Attacks by $M$. arenaria may be a constraint for mulberry cultivation; however, little information exists on the hostparasite relationships between this rootknot nematode and white mulberry. $M$. arenaria is often found in greenhouses in northern Europe, and is common in woody fruit crops in European countries $(12,14)$. The taxonomic identification of the $M$. arenaria population infecting these crops, including white mulberry, is of concern because this species is morphologically and geographically very close to $M$. hispanica Hirschmann. $M$. hispanica was first described parasitizing peach (Prunus persica L.) grown in Sevilla (8). In addition, populations of $M$. arenaria can be differentiated into two pathogenic races. Race 1 reproduces on peanut (Arachis hypogaea L.) and is distributed mainly in peanutgrowing areas. Race 2 is widespread and can reproduce on many hosts but not on peanut and pepper (Capsicum annuum L.) (18). Thus, accurate identification of $M$. arenaria populations and their pathogenic race characterization are needed for designing effective control measures in the context of sustainability and integrated pest management. This is especially important in root-knot nematodes, since host-plant resistance to reduce the initial nematode population density is scarce among crop plants (18). Furthermore, the extent of crop growth impairment by the nematode is influenced by nematode population density, with a minimum population density determining the threshold for measurable yield loss (the tolerance limit) (19). The objectives of this study were to determine: first, the taxonomic identity of the $M$. arenaria population infecting white mulberry; second, the histopathology in nematodefeeding sites on white mulberry roots; and third, the relationship between initial population density of the nematode and growth of white mulberry seedlings under greenhouse conditions.

\section{MATERIALS AND METHODS}

Nematode diagnosis and pathogenicity. The root-knot nematode infecting white mulberry was identified by means of microscopic observations and isozyme characterization of specimens (13). Samples of white mulberry feeder roots together with bulk soil were taken with a shovel from the upper $20 \mathrm{~cm}$ of soil from each of two home gardens at La Carlota (Córdoba province) and Utrera (Sevilla province) in southern Spain. Second-stage juveniles and males extracted from roots and soil (1), and females recovered from infected root tissues, were mounted in glycerin. Nematode anatomy of glycerin infiltrated specimens were examined by light microscopy. Single- or five-specimen groups of young egg-laying females were studied by isozyme electrophoretic methods (13).

For pathogenicity studies, the population of root-knot nematodes collected from infected white mulberry and a population of $M$. hispanica infecting peach in Sevilla, Spain, were used for a comparative study of $M$. arenaria-race differentials. Inoculum of $M$. arenaria consisted of eggs and second-stage juveniles collected with sodium hypochlorite (9). Inoculum of $M$. hispanica was first increased in tomato (Lycopersicum esculentum Mill. 'Rutgers') and extracted as that for $M$. arenaria. Twentyday-old seedlings of cotton (Gossypiun hirsutum L. 'Delta Pine'), peanut 'Florunner', pepper 'Early California Wonder', tobacco (Nicotiana tabacum L. 'NC 95'), tomato 'Rutgers', and watermelon (Citrullus vulgaris Schad. 'Charleston Grey'), were transplanted (one per pot) into 1-liter clay pots filled with autoclaved field soil. Two days later individual seedlings were inoculated by adding $10 \mathrm{ml}$ of a suspension 
containing 10,000 eggs and juveniles of the $M$. arenaria or $M$. hispanica populations. Plants that served as controls received the same amount of water. Plants were incubated in a greenhouse adjusted to $26 \pm 2^{\circ} \mathrm{C}$. There were four plants per nematode population-race differential combination. Fifty days after inoculation plants were uprooted and their roots gently washed, examined, and rated both for galls and egg masses developed.

Histopathology. Galled roots from naturally $M$. arenaria-infected white mulberry plants sampled at La Carlota (Córdoba) and from plants artificially infected in the inoculum-density plant-growth experiment were selected for histopathological studies. Roots were gently washed free of soil and debris, and individual galls selected. Root segments of uninfected seedlings served as control. Galled and healthy root tissues were fixed in formaldehyde chromoacetic solution for $48 \mathrm{~h}$, dehydrated in a tertiary butyl alcohol series (40-70-85-90-100\%), and embedded in $58^{\circ} \mathrm{C}$-melting point paraf- fin for histopathological observations. Embedded tissues were sectioned with a rotary microtome. Sections 10 to $12 \mu \mathrm{m}$ thick were mounted on glass slides, stained with safranin and fast-green, mounted permanently in dammax xylene, examined microscopically, and photographed (10).

Inoculum-density plant-growth impairment relationship. Inoculum of $M$. arenaria was extracted (9) from white mulberry roots collected at La Carlota. This inoculum was increased in tomato 'Rutgers' inoculated as before and incubated in a greenhouse adjusted to $26 \pm 2^{\circ} \mathrm{C}$. Two months after inoculation, at the time that egg masses were well formed in the tomato roots, the inoculated plant roots were washed free of soil and finely chopped. To estimate the amount of eggs and juveniles formed in the chopped tissue, 10 5-g aliquots of infected chopped roots were suspended in $1 \%$ aqueous solution of sodium hypochlorite in 100-ml jars for 4 min (9). For inoculation, chopped infected roots were thoroughly mixed with $3 \mathrm{~kg}$ of steam-sterilized sandy soil and the mixture was used as inoculum within a range of inoculum densities. Appropriate amounts of this inoculum were mixed with a potting mixture of $97.5 \%$ steam-sterilized sandy soil (sand $88 \%$, silt $5 \%$, clay $7 \%$ ) and $2.5 \%$ organic matter, to reach a population

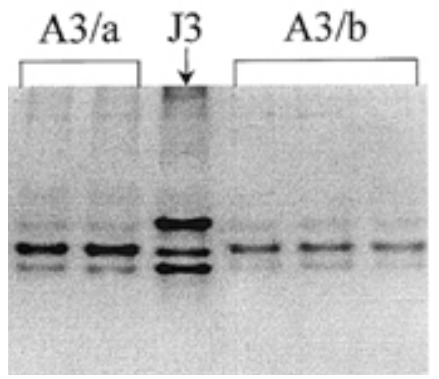

Fig. 2. Meloidogyne arenaria race 2. Esterase electrophoresis pattern of protein homogenates from five (A3/a) and single young egg-laying females $(\mathrm{A} 3 / \mathrm{b}) . \mathrm{J} 3=$ M. javanica (reference population).
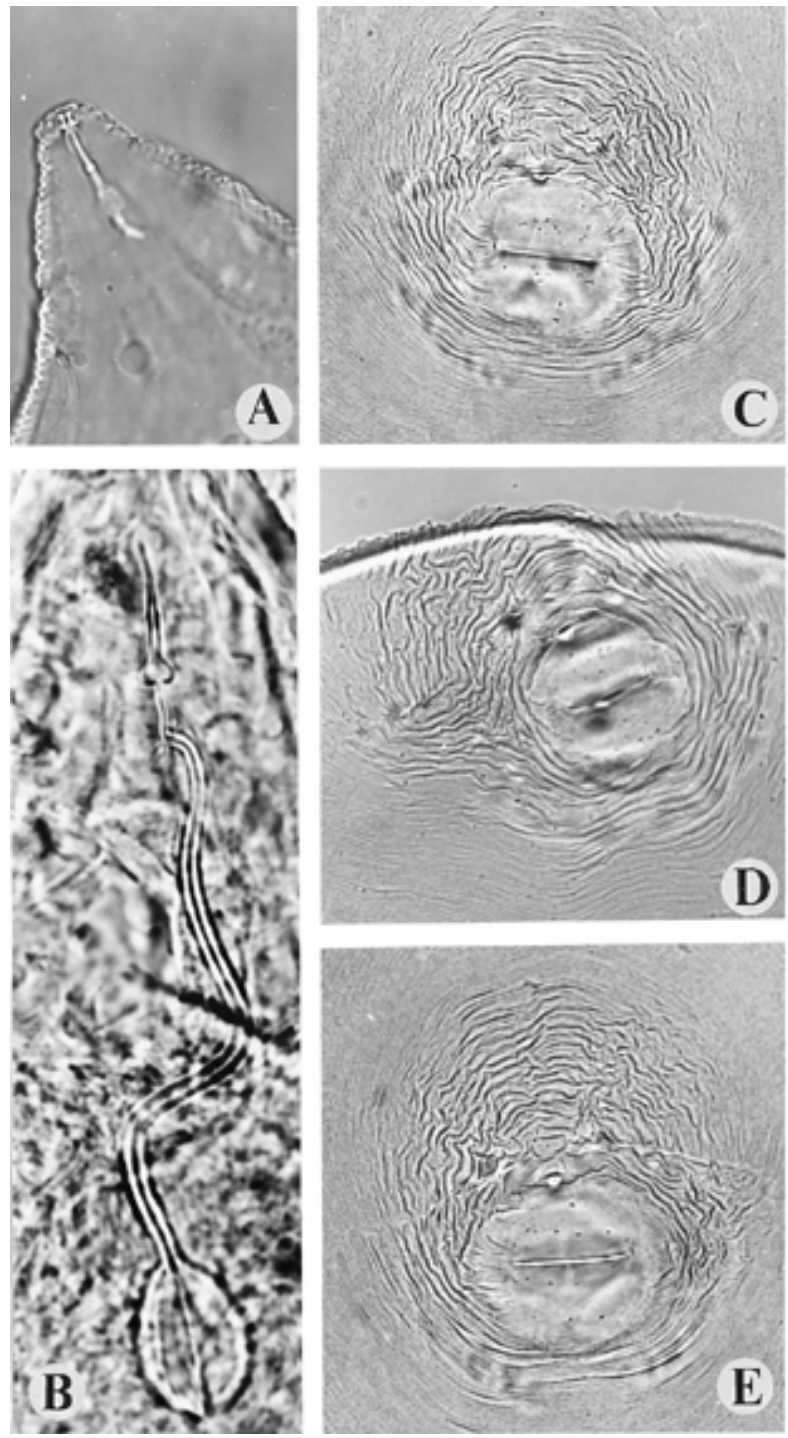
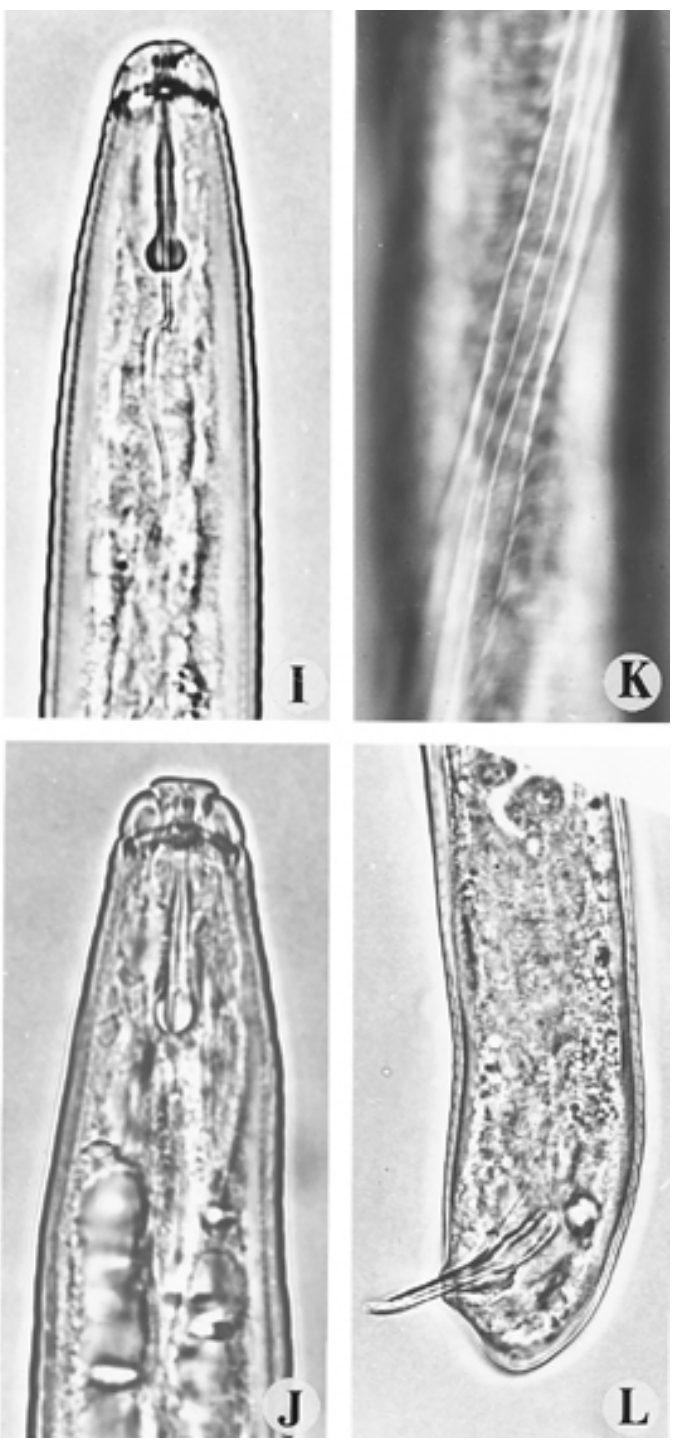

Fig. 1. Diagnostic features of Meloidogyne arenaria. A and B, Female anterior regions. C, D, and E, Female perineal patterns. F, G, and H, Second-stage juvenile. I and $\mathbf{J}$, Male anterior region. K, Lateral fields of male at mid-body. L, Male tail region; ep = excretory pore. 

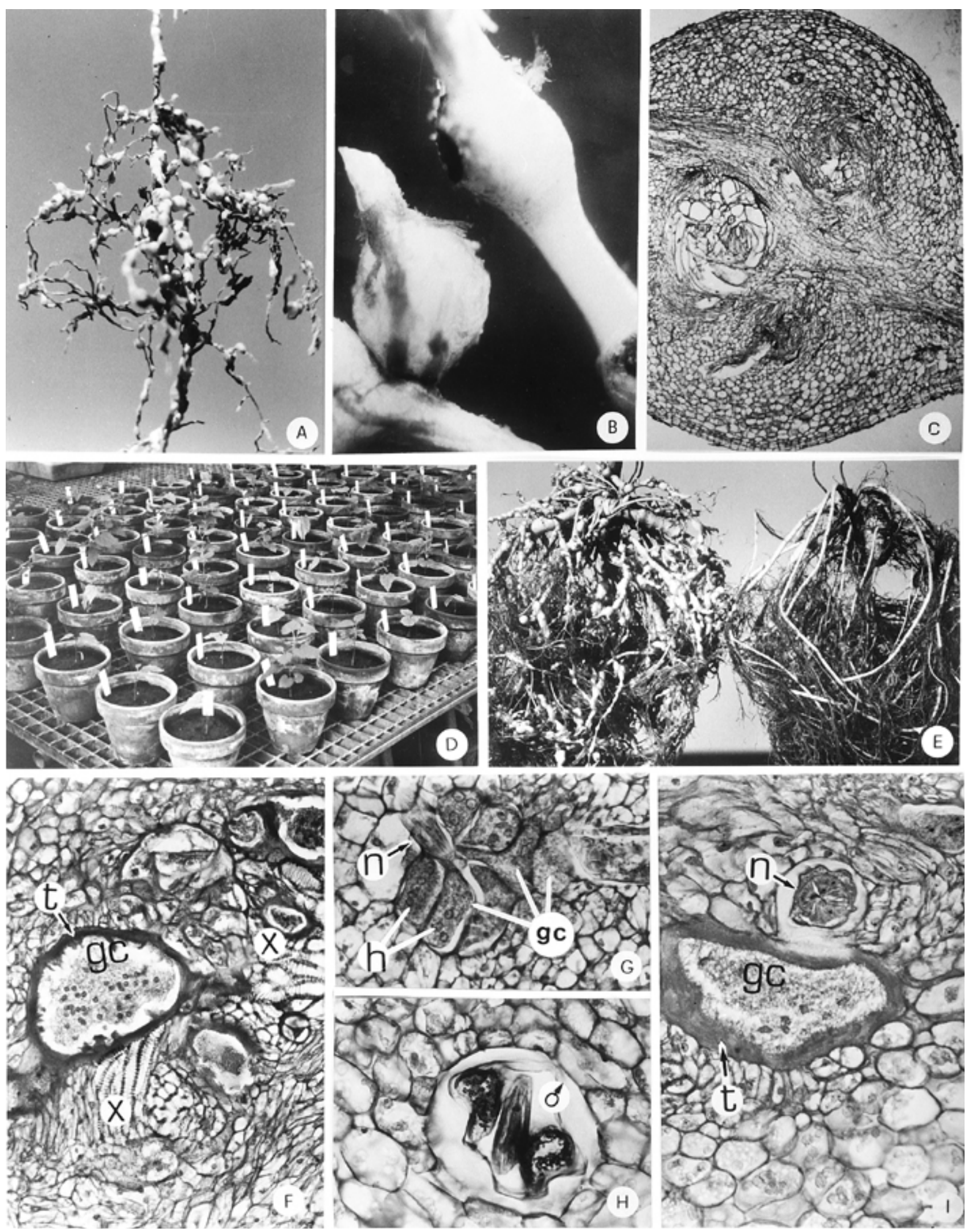

Fig. 3. Host-parasite relationships between Meloidogyne arenaria race 2 and white mulberry. A, and B, Galled roots from naturally infected plants, showing spherical galls. C, Longitudinal section of naturally infected roots showing giant cells and galling induced by $M$. arenaria. D, Display of plants artificially inoculated with $M$. arenaria showing marked reduction in shoot growth. E, Root systems of plants artificially inoculated with 1,024 eggs $+\mathrm{J}_{2} / \mathrm{cm}^{3}$ of soil of M. arenaria (left) and uninoculated control (right), respectively. F, G, H, and $\mathbf{I}$, Transverse sections of roots from plants artificially inoculated with $M$. arenaria. Abbreviations: $\mathrm{gc}=$ giant cell; $\mathrm{h}=$ hypertrophic nucleus; $\mathrm{n}=$ nematode; $\mathrm{t}=$ thickened cell wall; $\mathrm{x}=\mathrm{xylem}$. 
density of $0,0.125,0.25,0.5,1,2,4,8,16$, $32,64,128,256,512$, and 1,024 eggs and juveniles $/ \mathrm{cm}^{3}$ soil, and $600-\mathrm{ml}$ clay pots were filled with the infested soil mixture. A single, 2-month-old seedling of white mulberry 'Superior' was transplanted into each pot. There were eight pots for each inoculum density, arranged in a randomized complete block design in a greenhouse at $26 \pm 2^{\circ} \mathrm{C}$. Three months after transplanting, top fresh weight and height of plants were recorded. Plants were uprooted, the roots washed free of adhering soil and weighed, and eggs and juveniles in the egg masses in roots were extracted by the sodium hypochlorite method (9). Nematodes in soil were extracted by the modified Coolen's method $(1,4)$. The final nematode population densities were calculated as the total of that from roots and soil. The relationship between plant growth (indicated by the top fresh weight and height of plants) and the initial nematode population density was determined by fitting the data to the Seinhorst model: $y=$ $m+(1-m) z^{\mathrm{P}-\mathrm{T}}$ when $P \geq T$, and $y=1$ when $P<T(19,20)$. In this model, $y=$ relative value of the plant growth parameter; $m=$ minimum $y$ value ( $y$ at a very large initial nematode population density); $P=$ the initial nematode population density; $T$ $=\mathrm{a}$ tolerance limit (initial population at which plant growth is not impaired) and $z$ is a constant $>1$ reflecting nematode damage, with $z^{-\mathrm{T}}=1.05$ (19). The Seinhorst equation was fitted using the SeinFit program (21). The coefficient of determination $\left(R^{2}\right)$ and the residual sum of squares were used to indicate goodness-of-fit of data to the model.

\section{RESULTS AND DISCUSSION}

Nematode diagnosis and pathogenicity. Detailed morphometric observations based on the sampled second-stage juveniles, shape of male stylet knobs and features of the female perineal pattern (Fig. 1) agreed with those that characterize $M$. arenaria (15). The isozyme electrophoretic analyses of single- and five-specimen groups of young egg-laying sampled females (Fig. 2) revealed the esterase pattern that is characteristic of $M$. arenaria (6). Inoculations of the $M$. arenaria race differentials indicated that the population of the root-knot nematode from white mulberry in southern Spain is not virulent to cotton, peanut, and pepper, but is virulent to tobacco, tomato, and watermelon. Therefore, this population was identified as $M$. arenaria race 2 . The pattern of disease reactions induced by the population of $M$. hispanica in the differentials host was the same than that induced by $M$. arenaria. Therefore, these two species of root-knot nematodes are closely related both taxonomically and biologically.

Histopathology. Galls occurred either singly or in clusters which encircled the entire root perimeter. In this latter case the root diameter was 2 to 6 times larger than that of uninfected roots (Fig. 3). More than $45 \%$ of individual galls selected at random contained an egg mass. Usually, galls contained more than one nematode female. Observations of stained root sections revealed both tissue hypertrophy and hyperplasia, as well as disorganization and disruption of xylem elements and primary phloem cells. Nematode feeding sites comprised 3 to 8 giant cells that surrounded the lip region of a single female. Undersized feeding cells were associated with pre-adult males. Active multinucleated giant cells contained granular cytoplasm, thickened cell wall, and numerous hypertrophied nuclei and nucleoli. Dense giant cell cytoplasm lined deeply stained thick walls. The histological and anatomical changes induced by $M$. arenaria to mulberry roots were similar to those de- scribed for other root-knot nematode species infecting fruit trees $(11,14,22)$.

Inoculum-density plant-growth impairment relationship. The inoculum densities of the nematode included in the study impaired growth of mulberry plants (Fig. 3). The relationship between the top fresh weight and height of plants and the initial nematode population density was appropriately described by the Seinhorst equation (Fig. 4). Symptoms of attack by $M$. arenaria race 2 and reduction of plant top growth were evident 10 days after inoculation even with an initial population density of $P i=16$ eggs and juveniles $/ \mathrm{cm}^{3}$ soil. Reduction of plant top growth was also evident at lower initial population densities 20 days later. The white mulberry tolerance limits $(T)$ to $M$. arenaria race 2 were 1.1 and 1.38 eggs and juveniles $/ \mathrm{cm}^{3}$ soil for height plant and top fresh weight,

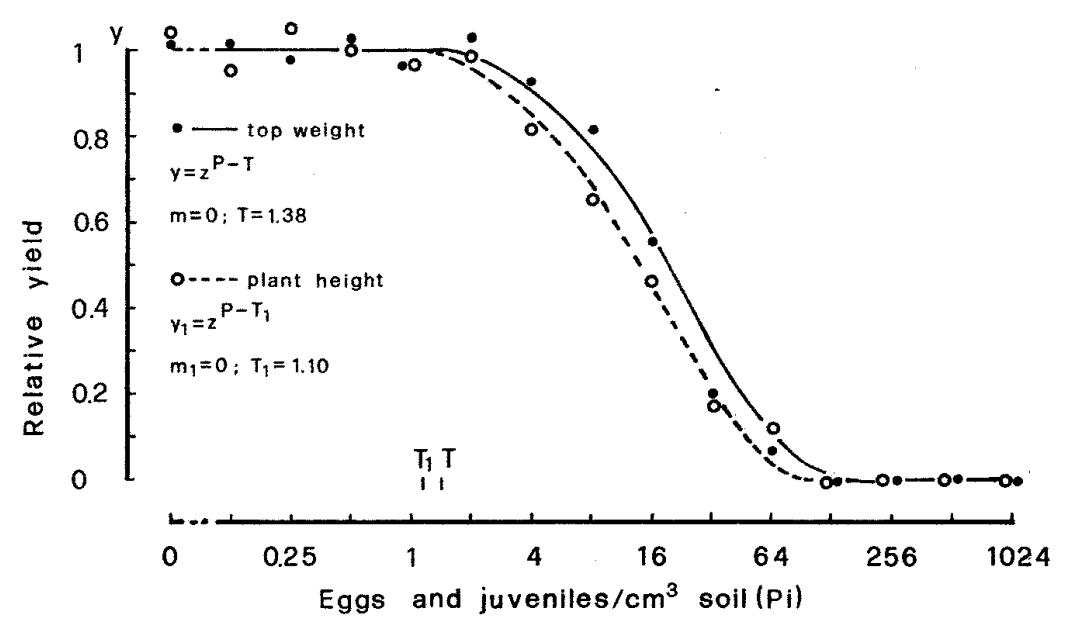

Fig. 4. Relationship between initial population densities (Pi) of a population of Meloidogyne arenaria race 2 from Spain and relative top fresh weight and height of white mulberry plants grown in pots at $26 \pm 2{ }^{\circ} \mathrm{C}$ in the greenhouse for 3 months. Actual data are presented for top weight $(\bullet)$ and plant height (O). Solid and dashed lines represent the predicted model. Statistics for fitted models of top and plant height were: $R^{2}=0.84$, Sum of squares $=16.31$; and $R^{2}=0.90$, Sum of squares $=154.16$, respectively.

Table 1. Relationship between initial population density of Meloidogyne arenaria race 2 ( $P i$, eggs and juveniles per $\mathrm{cm}^{3}$ soil) and final population density $(P f)$ and reproduction rate $(P f / P i)$ in white mulberry seedlings ${ }^{\mathrm{a}}$

\begin{tabular}{ccc}
\hline Initial population density $(\boldsymbol{P} \boldsymbol{i})$ & Final population density $(\boldsymbol{P} \boldsymbol{f})$ & Reproduction rate $(\boldsymbol{P f} / \boldsymbol{P} \boldsymbol{)})$ \\
\hline 0.125 & 20.6 & 164.8 \\
0.25 & 108.7 & 434.8 \\
0.5 & 135.2 & 270.4 \\
1 & 99.2 & 99.2 \\
2 & 91.8 & 45.9 \\
4 & 68.4 & 17.1 \\
8 & 86.7 & 10.8 \\
16 & 42.2 & 2.6 \\
32 & 20.8 & 0.6 \\
64 & 15.1 & 0.2 \\
128 & 50.6 & 0.4 \\
256 & 21.0 & 0.1 \\
512 & 26.9 & 0.1 \\
1,024 & 23.1 & 0 \\
\hline
\end{tabular}

${ }^{a}$ Two-month-old white mulberry seedlings were transplanted (one per pot) into a potting mixture infested with the appropriate Pi. Plants were grown in a greenhouse adjusted to $26 \pm 2^{\circ} \mathrm{C}$ for 3 months. 
respectively (Fig. 4). The minimum relative value $(m)$ for plant height and top fresh weight was 0 at $P i \geq 64$ and $P i \geq 128$ eggs and juveniles $/ \mathrm{cm}^{3}$ soil, respectively. The maximum nematode reproduction rate (Pf/Pi; $P i=$ initial population density, $P f$ $=$ final popuation density) was 434.8 at $P i$ $=0.25$ eggs and juveniles $/ \mathrm{cm}^{3}$ of soil. This reproduction rate decreased as the initial nematode population increased (Table 1). Reduction of nematode reproduction rate with increasing initial nematode inoculum density has been reported associated with infections of several crops by $M$. incognita (3-5). Our findings could be a consequence of nematode competition for nutrients or root tissue availability (feeding sites), as a result of which a smaller proportion of the inoculum would develop succesfully.

Results demonstrated that $M$. arenaria race 2 has the potential to severely impair growth of white mulberry. The tolerance limit of this plant to the nematode is as low as approximately $1 \mathrm{egg} / \mathrm{cm}^{3}$ soil. An initial population density of this parasite exceeding $64 \mathrm{eggs} / \mathrm{cm}^{3}$ soil had a lethal result for white mulberry. Our results on pathogenicity of $M$. arenaria on white mulberry agreed with those of other researchers in China $(23,24)$ and India $(7,16)$, who found that $M$. arenaria and $M$. incognita (Kofoid et White) Chitwood significantly reduced the number of leaves and plant growth of white mulberry trees. Therefore, control measures need to be implemented in order to guarantee production of nematode-free planting stocks and to avoid spread of the nematode to areas not infested.

\section{ACKNOWLEDGMENTS}

We thank G. Zaccheo and F. Catalano for their technical assistance in conducting of the greenhouse experiments; D. Esmenjaud from INRA, Antibes (France) for kindly providing a sample population of $M$. hispanica from roots of infected tomato; I. de O. Abrantes and C. Santos, Departamento de Zoologia, Universidade de Coimbra, Portugal, for their help with the isozyme electro- phoretic studies; and $\mathrm{H}$. Rapoport from IAS-CSIC for her critical revision of the manuscript.

\section{LITERATURE CITED}

1. Coolen, W. A. 1979. Methods for extraction of Meloidogyne spp. and other nematodes from roots and soil. Pages 317-330 in F. Lamberti and C. E. Taylor, eds. Root-knot Nematodes (Meloidogyne species) Systematics, Biology and Control. Academic Press, London.

2. Das, B. C, and Krishnaswami, S. 1965. Some observation on interspecific hybridation in mulberry. Indian J. Seric. 4:1-4

3. Di Vito, M. 1986. Population densities of Meloidogyne incognita and growth of susceptible and resistant pepper plants. Nematol. Mediterr. 14:217-221.

4. Di Vito, M., Greco N., and Carella, A. 1985. Population densities of Meloidogyne incognita and yield of Capsicuum annuum. J. Nematol. 17:45-49.

5. Di Vito, M., Greco N., and Carella, A. 1986. Effect of Meloidogyne incognita and importance of the inoculum on the yield of eggplant. J. Nematol. 18:487-490.

6. Esbenshade, P. R., and Triantaphyllou, A. C. 1990. Isozyme phenotypes for the identification of Meloidogyne species. J. Nematol. 22:10-15.

7. Govindaiah, D., and Sharma, D. D. 1994. Root-knot nematode, Meloidogyne incognita infecting mulberry, a review. Indian J. Seric. 33:110-113.

8. Hirschmann, H. 1986. Meloidogyne hispanica n.sp. (Nematoda: Meloidogynidae), the 'Seville Root-Knot Nematode'. J. Nematol. 18:520-532.

9. Hussey, R. S., and Barker, K. R. 1973. A comparison of methods of collecting inocula of Meloidogyne spp., including a new technique. Plant Dis. Rep. 57:1025-1028.

10. Johansen, D. A. 1940. Plant microtechnique. McGraw-Hill Books, New York.

11. Kaplan, D. T., and Koevening, J. L. 1989. Description of host-parasite relationship of Meloidogyne christei with Quercus laevis. Rev. Nematol. 12:57-61.

12. Karssen, G., and Van Hoenselaar, T. 1998. Revision of the genus Meloidogyne Göeldi, 1892 (Nematoda: Heteroderidae) in Europe. Nematologica 44:713-788.

13. Karssen, G., Van Hoenselaar, T., VerkerkBakker, B., and Janssen, R. 1995. Species identification of root-knot nematodes from potato by electrophoresis of individual fe- males. Electrophoresis 16:105-109.

14. Marull, J., Pinochet, J., Felipe, A., and Cenis, J. L. 1994. Resistance verification in Prunus selections to a mixture of thirteen Meloidogyne isolates and resistance mechanisms of a peach-almond hybrid to $M$. javanica. Fundam. Appl. Nematol. 17:85-92.

15. Orton Williams, K. J. 1975. Meloidogyne arenaria C.I.H. descriptions of plant parasitic nematodes. Set 5, no. 62, C.A.B., St. Albans, UK.

16. Saha, S. S., Sinhababu, S. P., and Sukul, N. C. 1983. The effect of nematode infestation on mulberry plants and their effect on feeding silkworms Bombyx mori L. Nematologica 29:463-467.

17. Sarkar, A. 1990. Towards understanding the problem of breeding in mulberry, the factors involved in biometrical studies. Workshop in biometrical genetics. CSRTI, Myore, India.

18. Sasser, J. N., and Carter, C. C. 1985. An advanced treatise on Meloidogyne. Vol. I. Biology and control. North Carolina State Univ., Raleigh.

19. Seinhorst, J. W. 1965. The relationship between nematode density and damage of plants. Nematologica 11:137-154.

20. Seinhorst, J. W. 1979. Nematodes and growth of plants: formulation of the nematode-plant system. Pages 231-256 in F. Lamberti and C. E. Taylor, eds. Root-knot Nematodes (Meloidogyne species) Systematics, Biology and Control. Academic Press, London.

21. Viane, N. M., Simoens, P., and Abawi, G. S. 1997. SeinFit, a computer program for the estimation of the Seinhorst equation. J. Nematol. 29:474-477.

22. Vovlas, N., Di Vito, M., and Grammatikaki, G. 1993. Growth response of in vitro produced banana plantlets to Meloidogyne javanica in pots. Nematropica 3:203-208.

23. Wang, R. X., and Chen, Z. A. 1989. The identification of root-knot nematodes on mulberry. Acta Univ. Sept. Occ. Agric. 17:115116.

24. Wang, R. X., and Yang, Z. W. 1993. Damage by root-knot nematodes on mulberry tree. J. Northwest. College For. 8:27-32.

25. Yousseff, M. M. A. 1998. Population dynamics of plant parasitic nematodes associated with mulberry in Egypt. Pak. J. Nematol. 16:95-102.

26. Zhu, X. 1993. Benefit analysis of sericulture production of hilly regions of Shaanbei Loess Plateau. Acta Agric. Boreali-Occ. Sinica 2:5660. 